\title{
SEISMIC HAZARD ESTIMATION IN STABLE CONTINENTAL REGIONS: DOES PSHA MEET THE NEEDS FOR MODERN ENGINEERING DESIGN IN AUSTRALIA?
}

\author{
Trevor I. Allen ${ }^{1}$
}

(Submitted September 2019; Reviewed October 2019; Accepted December 2019)

\begin{abstract}
Damaging earthquakes in Australia and other regions characterised by low seismicity are considered low probability but high consequence events. Uncertainties in modelling earthquake occurrence rates and ground motions for damaging earthquakes in these regions pose unique challenges to forecasting seismic hazard, including the use of this information as a reliable benchmark to improve seismic safety within our communities. Key challenges for assessing seismic hazards in these regions are explored, including: the completeness and continuity of earthquake catalogues; the identification and characterisation of neotectonic faults; the difficulties in characterising earthquake ground motions; the uncertainties in earthquake source modelling, and; the use of modern earthquake hazard information to support the development of future building provisions.

Geoscience Australia recently released its 2018 National Seismic Hazard Assessment (NSHA18). Results from the NSHA18 indicate significantly lower seismic hazard across almost all Australian localities at the 1/500 annual exceedance probability level relative to the factors adopted for the current Australian Standard AS1170.4-2007 (R2018). These new hazard estimates have challenged notions of seismic hazard in Australia in terms of the recurrence of damaging ground motions. This raises the question of whether current practices in probabilistic seismic hazard analysis (PSHA) deliver the outcomes required to protect communities and infrastructure assets in low-seismicity regions, such as Australia. This manuscript explores a range of measures that could be undertaken to update and modernise the Australian earthquake loading standard, in the context of these modern seismic hazard estimates, including the use of alternate ground-motion exceedance probabilities for assigning seismic demands for ordinary-use structures.

The estimation of seismic hazard at any location is an uncertain science, particularly in low-seismicity regions. However, as our knowledge of the physical characteristics of earthquakes improve, our estimates of the hazard will converge more closely to the actual - but unknowable - (time independent) hazard. Understanding the uncertainties in the estimation of seismic hazard is also of key importance, and new software and approaches allow hazard modellers to better understand and quantify this uncertainty. It is therefore prudent to regularly update the estimates of the seismic demands in our building codes using the best available evidence-based methods and models.
\end{abstract}

\section{INTRODUCTION}

Forecasting seismic hazard in stable continental regions (SCRs) brings unique challenges to hazard modellers and practitioners in terms of the characterisation of seismic sources and their ground motions. By their very nature, SCRs experience significantly lower rates of seismicity compared to tectonic plate margins, such as New Zealand. As a consequence, the typical observation period of historical (or instrumental) seismicity is significantly shorter than the seismic cycle of rare large earthquakes that may generate damaging ground motions on any given fault. Critics of probabilistic seismic hazard analysis (PSHA) for use in SCRs often claim that the uncertainties in seismological knowledge are too large to allow modern hazard assessments to underpin earthquake loading codes. Further, some argue that any exceedance of mapped hazard is a failure of the method to correctly identify regions at risk. However, the PSHA methodology is defined such that the mapped values will be exceeded, and this should occur at a predefined probability of exceedance as stipulated in earthquake loading codes. In assessing the performance of seismic hazard maps, there will inevitably be some error and uncertainty around the observed exceedance rate due to the modelling uncertainty and natural randomness of earthquake events [1]. A key benefit of the PSHA framework, however, is the ability to include multiple sources of modelled uncertainty and to propagate these uncertainties through to the final hazard result [2]. Modern seismic hazard calculation software [e.g., 3] now enables improved characterisation of modelling uncertainties and can provide additional information regarding the utility and confidence of seismic hazard assessments for end users [e.g., 4, 5].

Seismic hazard assessments in SCRs are often more dependent on earthquake catalogues and the relationships between smallto-large earthquakes [e.g., 6] than in seismically active regions, with a high-dependence on the rates of small-magnitude earthquakes to forecast the occurrence rates for larger events of greater societal concern. The completeness of earthquake catalogues, together with changes in observatory practice over time delivers challenges in ensuring the catalogue provides a consistent representation of an earthquake's size over time, making the estimation of earthquake occurrence parameters 
highly sensitive to these practices and the constantly changing detection thresholds of the seismic networks.

The characterisation of seismic sources can be undertaken using several philosophical approaches, each of which are scientifically defendable. The use of multiple seismic source models allows for the exploration of epistemic uncertainty (i.e., uncertainties due to lack of knowledge) among different models. However, this may present further challenges in assessing the utility of different source-model types (e.g., smoothed or zoned seismicity) over different spatial scales and return periods of interest.

In Australia, the limited observation period is exacerbated by the sparse seismic recording network relative to the size of the continent. This means that even when a moderate-to-large earthquake does occur within the continental crust, it will often be poorly recorded in terms of its ground-motion accelerations. Consequently, the densification of seismic monitoring instrumentation is key for capturing strong-motion data from future large earthquakes. Nevertheless, the relative paucity in strong-ground motions recorded from Australian earthquakes presents challenges for the characterisation of earthquake ground-motions and the selection of appropriate ground-motion models (GMMs) for seismic hazard analysis [e.g., 7]. These models are commonly adopted from analogue tectonic regions. However, there are some unique characteristics for Australian earthquakes and recorded ground motions that make these decisions challenging in the absence of reliable locallydeveloped models.

In 2018, Geoscience Australia, together with contributions from the wider Australian seismology community, released a revised National Seismic Hazard Assessment [NSHA18; 8]. Relative to the seismic hazard map included in the AS1170.4-2007 (R2018), the NSHA18 leverages advances in earthquake-hazard science in Australia and analogue tectonic regions over the last three decades to offer many improvements over its predecessors as summarised in Allen et al. [5]. Through the NSHA18, peak ground acceleration (PGA) values at the 1/500 annual exceedance probability (AEP) across Australia have decreased, on average, by $72 \%$ relative to the earthquake hazard factors provided for localities in the Australian earthquake loading code, AS1170.4-2007 [9].

These new hazard estimates, coupled with changes to sitespecific probability factors $\left(k_{p}\right)$, which scale the 1/500 AEP hazard factors to different exceedance probabilities, have challenged notions of seismic hazard in Australia in terms of the recurrence times for damaging ground motions [10]. In light of this assessment, it is timely to review whether the groundmotion probability level of 1/500 AEP - as prescribed by the National Construction Code [11] for use in the AS1170.4 - is appropriate for the design of ordinary-use structures.

In this contribution, some of the challenges and uncertainties facing seismic hazard analysis in slowly deforming continental interiors are discussed and opportunities to overcome these challenges are considered. Moreover, opportunities to advance earthquake-hazard science and modernise building provisions for earthquake engineering professionals in Australia, and similar low-seismicity environments, are discussed in the context of the NSHA18 results.

\section{CHALLENGES FOR SEISMIC HAZARD ASSESSMENT IN STABLE CONTINENTAL REGIONS}

Given the typically low rates of natural seismicity, there are high degrees of uncertainty for PSHAs in any SCR. This uncertainty manifests in many ways: identification and characterisation of active neotectonics faults, accurate and consistent earthquake catalogues, ground-motion characterisation, and seismic-source modelling to name a few. While these challenges contribute significant uncertainties in the assessment of seismic hazard for SCRs, there are several opportunities to improve our knowledge in PSHA component models. These opportunities are discussed below.

\section{Identification and Characterisation of Active Faults}

Unique challenges are faced in modelling the seismic hazard from active (or neotectonic) faults in intraplate regions. Low fault slip rates relative to landscape modification rates often lead to poor discoverability of fault sources, and result in incomplete characterisation of rupture behaviour [e.g., 12]. To underscore this point, none of the nine historical surfacerupturing earthquakes occurring within the Australian continent could have been identified from a topographic signature prior to their causative event $[13,14]$. However, regional and local assessments have demonstrated that fault sources assigned with activity rates consistent with paleoseismic observations can significantly impact on probabilistic seismic hazard assessments in Australia [8, 12, 13, 15, 16], particularly for lower exceedance probabilities where there may be several fault sources that contribute to the total seismic hazard.

Incompleteness of the neotectonic fault record might be expected to result in an under-estimate of the hazard, especially in regions where landscape modification rates are comparable to, or exceed the rates of tectonic relief building [12, 17]. However, the incompleteness in the fault record might be counterbalanced by the knowledge that faults with lower slip rates and thus, low potential of discovery, are not expected to contribute significantly to ground-motion hazard for exceedance probabilities that may affect ordinary-use structures (e.g., 1/475 or 1/2475 AEP) [e.g., 13, 14]. Nevertheless, the seismogenic characteristics (in terms of frequency, magnitude and temporal variability) of various combinations of geology, crustal architecture and geological history are underexplored and relatively poorly understood in terms of their seismic potential. These are significant challenges that face seismic hazard modellers in SCRs. However, new, openly-available high-resolution topographic datasets (e.g., elevation.fsdf.org.au/) are now becoming available across much of the continent. These data, combined with dedicated field investigations could enable improved discoverability and seismogenic characterisation of neotectonic faults across Australia. Furthermore, studies investigating the potential for earthquake spatial and temporal clustering behaviour among faults will no doubt improve our ability to model the likelihood of earthquake ruptures on known faults across the continent [18, $19]$ and in analogue regions [20].

\section{Developing Consistent Catalogues}

Earthquake catalogues that have well-defined magnitudecompleteness thresholds with magnitudes that are uniformly expressed using consistent magnitude types are fundamental inputs into any PSHA and are used to establish earthquake occurrence rates for a given area source zone [e.g., 21] or spatially varying smoothed seismicity models [e.g., 22]. In practice, neither the magnitude of completeness nor the consistency of magnitude calculation procedures over time can be known to a high degree of certainty throughout Australia. Consequently, the reliance on this information to deliver forecasts for large earthquakes can contribute large uncertainties in seismic hazard.

Prior to the early 1990s, most Australian seismic observatories relied on the Richter [23] local magnitude $\left(M_{L}\right)$ formula developed for southern California [21]. At regional distances (where many remote earthquakes are recorded), the Richter scale tends to overestimate $M_{L}$ relative to modern Australian 
magnitude formulae [e.g., 24] by up to half an order of magnitude or more [25]. Consequently, historical earthquakes of the same energy release could have very different magnitudes depending on their location relative to the recording network.

Modern PSHAs rely on earthquake catalogues consistently expressed in terms of moment magnitude, $M_{W}$. However, $M_{W}$ is still not commonly calculated for small-magnitude local events by many national networks, including Australia. For use in earthquake recurrence calculations [i.e., 6], magnitude conversion equations are often applied to convert $M_{L}$ to $M_{W}$. Unless these conversions are time-dependent, they commonly assume that $M_{L}$ estimation has been consistent for the observation period. Consequently, for earthquakes in Australia, there is a need to correct pre-1990 magnitude estimates to ensure continuity with current observatory magnitude estimation methods [26]. Ideally, this could be achieved using original amplitude and period picks. However, this presently cannot be easily achieved for pre-digital (and even some earlydigital) data. Allen et al. [5] explores the impact of the aforementioned adjustments to catalogue magnitudes on overall hazard. This study shows that the combined effects of $M_{L}$ adjustments and $M_{W}$ conversions contribute to reductions in hazard by factors of generally two or less on a national scale. These hazard reductions are spatially variable and become negligable in far northern Australia because the hazard is dominated by the regional plate boundary sources [27]. Consequently, the hazard in these regions is not significantly affected by adjustments in the local earthquake catalogue.

To address ongoing challenges for catalogue improvement, Geoscience Australia is digitising printed and hand-written observations preserved on earthquake data sheets. Once complete, this information will provide a valuable resource that will allow for further interrogation of pre- and early-digital data and enable refinement of historical catalogues to improve future national-scale seismic hazard estimation.

\section{Ground-Motion Characterisation}

The aleatory variability within, and epistemic uncertainty between ground-motion attenuation models is often considered to contribute some of the largest uncertainties in PSHAs [28, 29]. This is particularly true of SCRs such as Australia with few data recorded from moderate-to-large earthquakes. Nevertheless, ground-motion models (GMMs) that predict the intensity of ground shaking for a given magnitude and distance (on a given site class) form an essential component to modern PSHAs. Whilst there is a paucity of data from which to develop empirical GMMs, stochastic [e.g., 30, 31, 32] and physicsbased simulation approaches [e.g., 33] can be developed through the use of local earthquake source and propagation path characteristics [e.g., 34].

The number of GMMs available for use in PSHAs continues to grow rapidly [e.g., 35, 36] and choosing appropriate models for any given tectonic region type is a challenging task. Whilst tectonic analogues can be a reasonable first-order approximation for GMM selection, there can be regional differences in ground-motion attenuation among SCRs that may limit the extent to which GMMs from tectonic analogues can be used $[37,38]$.

Various measures can be applied to provide quantitative rankings of GMMs from local and analogue tectonic environments [e.g., 39]. Whilst these quantitative analyses can be informative, care should be taken not to over-interpret the results, particularly given the sparsity of ground-motion datasets available in Australia [7], and for other regions of low seismicity. For example, the use of quantitative ranking measures often reflect the overall performance of a model against the entire ground-motion dataset. However, this may undermine some desirable features of a GMM, such as model performance against near-field or long-period data [e.g., 40]. Consequently, there is an ongoing need for professional judgement in the selection of GMMs for PSHAs for Australia.

Additionally, Australia possesses some ground-motion characteristics that are largely unique to the continent, which mean that it is difficult to simply use "off-the-shelf" GMMs from tectonically analogous regions. For example, many of the earthquakes occurring in Western Australia occur in the upper few kilometres where low-angle crustal detachments [e.g., 41] combined with high near-surface crustal stresses [e.g., 42] appear to favour the occurrence of earthquakes at shallow depths. The very shallow earthquake hypocentres combined with a shallow lower-velocity crustal layer allow for the excitement of large $R g$ phases [33] that dominate acceleration spectra at periods near 1 second [e.g., 40] (Figure 1).

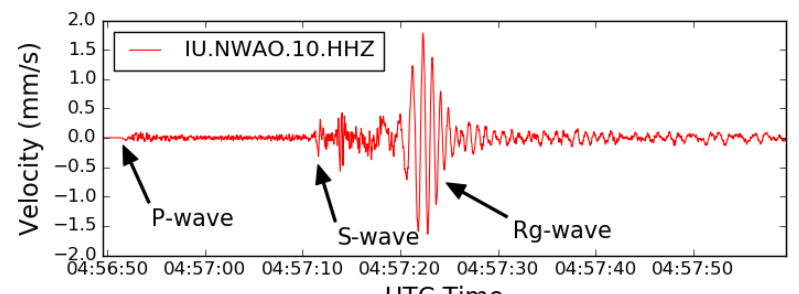
UTC Time

Figure 1: An example of a velocity seismogram, recorded at Narrogin (NWAO) during the 16 September $2018 M_{W} 5.3$

Lake Muir, southwestern Western Australia earthquake. The station was approximately $170 \mathrm{~km}$ from the earthquake's epicentre. The record shows a strong $\mathrm{Rg}$ phase arrivals at longer periods (indicating a shallow rupture depth), which is characteristic of seismic recordings from this region.

Other unique ground-motion characteristics are observed in northern Australia. At its nearest, Australia is just over $400 \mathrm{~km}$ from an active convergent plate margin. This complex tectonic region combines active plate subduction and the collision of the Sunda-Banda Arc with the Precambrian North Australian Craton (NAC) at the Timor Trough.

Ground-motions generated from earthquakes on these sources have particular significance for northern Australian communities and infrastructure projects, with several large earthquakes in the Banda Arc region having caused ground shaking-related damage in Darwin over the historical period $[43,44]$. There are very few regions of the world where cold cratonic crust abuts a convergent tectonic margin with subduction earthquakes. Most ground motions recorded from earthquakes in typical subduction environments are highly attenuated as they travel through volcanic back-arc regions [e.g., 45]. However, seismic energy from earthquakes in the northern Australian plate margin region are efficiently channelled through the low-attenuation NAC [46, 47], which acts as a waveguide for high-frequency earthquake shaking [48]. The low rate of attenuation means that choosing groundmotion models for these subduction earthquakes that reflect both the earthquake source and attenuation characteristics of the region is a major challenge in PSHAs.

There is still much to do in terms of characterising groundmotions from Australian earthquakes for use in seismic hazard assessments, particularly due to the sparse recording networks and low rates of seismicity. However, knowledge in the character of ground-motion attenuation throughout the continent is gradually evolving. Data acquired from recent Australian earthquakes [14, 49] will have significant utility to enable more informed choices for GMMs for future hazard assessments and will support future empirical and simulated 
ground-motion studies for the nation. Underpinning this is the need for a database of uniformly-processed ground motion records from Australian earthquakes and accompanying site characterisation information, similar to those developed for New Zealand [e.g., 50, 51]. Ongoing enhancements to seismic monitoring networks will also provide opportunities to augment existing ground-motion datasets.

\section{Seismic-Source Characterisation}

Seismic source (or rate) models describe the annualised magnitude-frequency occurrence likely within a particular source zone, or spatially varying grid of point sources. Alternative seismic source models combined through a weighted logic-tree approach are often used in PSHAs to capture the epistemic uncertainty of multiple scientifically defensible alternatives [e.g., 2, 52]. The calculated groundmotion hazard can be very sensitive to the location of classical area-source-model boundaries [53]. The placement of these boundaries is often subjective and can be dependent on a modeller's professional judgment and experience. Furthermore, if the modeller only considers one zone-based seismic-source model, the strongest hazard gradients will often tend to occur in the vicinity of the area source boundaries. Because the areasource boundaries developed by two (or more) independent modellers are unlikely to be duplicated exactly, the use of multiple seismic source models will introduce "fuzzy" sourcezone boundaries and will act to damp these strong spatial hazard gradients. In the NSHA18, five different seismic source-model classes were used [8]. These include:

- Background area source zones that use broad geographic zones within which large earthquakes can occur anywhere with equal probability. These are typically models with 20 or fewer area-source zones on a national scale;

- Regional area source zones are smaller in size and assume the spatial distribution of seismicity is non-uniform at the scale of background source zones. Consequently, the distribution of historical seismicity is useful to forecast future earthquake occurrence. These are typically models with 30 or more area sources;

- Smoothed seismicity data-driven models that yield spatially-varying earthquake occurrence rates by smoothing the observed rates of earthquake occurrence with a given smoothing kernel [e.g., 54]. These models assume that historical seismicity is a good predictor of future seismic hazard;

- $\quad$ Seismotectonic models (e.g., regional zones combined with a fault-source model) [55], and;

- $\quad$ Smoothed seismicity combined with a fault-source model.

The latter two source-model types that include fault sources represent minor variations on the regional and smoothed seismicity models. The NSHA18's fault-source model included some 356 onshore faults and 23 offshore faults, modelled as simplified planes and assigned with a general dip and rake direction [55, 56]. Slip rates are calculated from: 1) displaced strata of known age; 2) estimated from surface expression combined with knowledge of landscape modification rates (e.g., erosion and/or deposition), and/or; 3) are estimated by proxy from similar neotectonic settings. In a small number of instances slip rate data are available from paleoseismic trenching investigations [e.g., 18, 57, 58].

In total, the NSHA18 used 19 independent seismic-source models for estimating the rates of earthquake occurrence at any given location in continental Australia [5, 8]. These source models were weighted through a logic-tree framework $[59,60]$ and each provide a unique spatial representation of hazard (Figure 2). As demonstrated in Figure 2, the consequence of using background source models that distribute earthquake rates uniformly across large areas (Figure 2a) may lead to lower seismic hazard values in regions where seismicity has been relatively stationary in the modern instrumental era [21] (Figure $2 b-c)$.
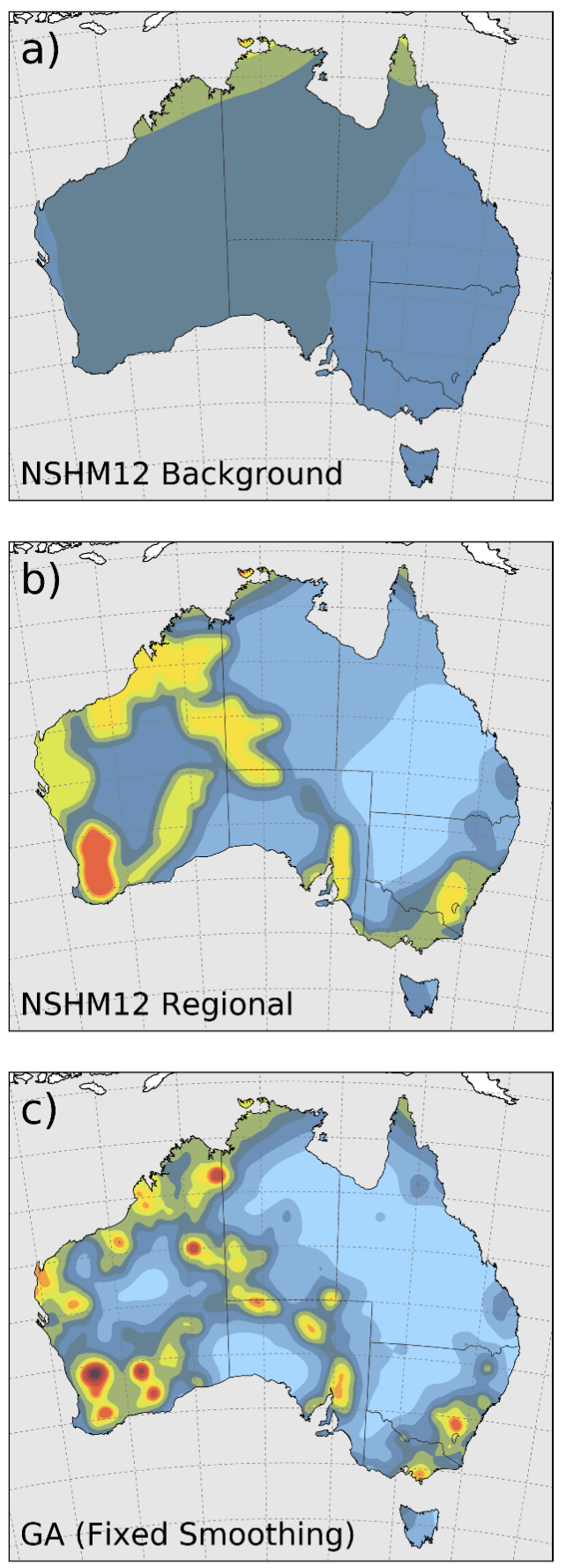

$\begin{array}{lllllll}0.0 & 0.01 & 0.02 & 0.04 & 0.06 & 0.12 & 0.24\end{array}$

PGA $10 \%$ in $50-$ Year Mean Hazard (g)

Figure 2: The mean 10\% in 50-year PGA hazard expressed by three end-member source model types as used in the NSHA18: a) broad background sources [NSHM12; 61]; b) regional area sources [NSHM12; 61], and; c) smoothed seismicity [GA Fixed Kernel; 22]. 
One challenge for forecasting seismic hazard for SCRs is the long recurrence times for large earthquakes. While the use of background source models may need to be reconsidered for eastern Australia, there is mounting evidence in central and western Australia to suggest that seismicity is non-stationary over time and could vary over decade-long timescales $[13,17$, 21]. Therefore, the use of background source models that allow for large earthquakes to migrate spatially over longer time horizons may become more important. Furthermore, these source-model-types allow for rare "black swan" events to occur, albeit with low probabilities, in regions where previous large earthquakes have not been observed in the historic or neotectonic record. A prime example of these event types is the 1988 Tennant Creek sequence, where three large $M_{W}>6.0$ earthquakes occurred within a 12 hour period in a location that had effectively been aseismic during historical times [62]. Additionally, the apparent anti-correlation of some neotectonic fault scarps and present-day seismicity suggests that these rare events should be modelled over broad regions [14].

Hazard modellers must therefore strike a balance between these end-member models when calculating seismic hazard at national scales. Furthermore, the relative weight placed on a specific model type (e.g., smoothed seismicity, regional or background) might vary spatially, and also on the target exceedance probability of interest [e.g., 63].

\section{OPPORTUNITIES TO UPDATE BUILDING CODES}

The results of the NSHA18 have challenged notions of seismic hazard in Australia and have raised questions over the suitability of the probability level - prescribed by the National Construction Code [NCC; 11] and as applied in the AS1170.4 to determine seismic demands for the design of ordinary-use structures. Whilst changing the AS1170.4 exceedance probability level would be a major departure from previous earthquake loading standards, it would bring it into line with other international building codes in similar tectonic environments. Additionally, it would offer opportunities to further modernise how seismic demands are considered in Australian building design. In particular: 1) the scaling of seismic hazard with different probabilities of exceedance (i.e., the shape of hazard curves); 2) the use of uniform hazard spectra to replace and simplify the spectral shape factors, which do not deliver uniform hazard across all oscillation periods; 3 ) the updated site amplification factors to ensure continuity with modern ground-motion models, and; 4) the potential to define design ground motions in terms of uniform collapse risk rather than uniform hazard.

The AS1170.4 was recently amended by Standards Australia's BD-06-11 Technical Subcommittee [64]. The amended AS1170.4-2007 (R2018) retains seismic demands developed in the early 1990s [65] and introduces a minimum hazard design factor of $Z=0.08 \mathrm{~g}$, partly due to concerns that modern $1 / 500$ AEP hazard factors proposed in the NSHA18 would not assure life safety throughout the continent. Herein, we discuss opportunities to modernise the standard and allay these concerns, should the BD-06-11 Technical Subcommittee seek to update the earthquake loading code to reflect the latest evidence-based science for future standards.

\section{Shape of Hazard Curves}

One of the major differences in seismic hazard between active tectonic regions (ATRs) and SCRs is how the shape of the hazard curve changes with decreasing probabilities of exceedance. Figure 3a shows a comparison of seismic hazard curves for selected Australian sites as calculated in the NSHA18 relative to hazard curves based on the OpenQuake implementation [e.g., 66] of the 2010 national seismic hazard model of New Zealand [67]. This figure clearly shows the absolute differences in seismic hazard, as might be expected from relative earthquake occurrence rates between Australia and New Zealand. However, by normalising the curves to an arbitrary exceedance probability (Figure $3 b$ ), the difference in the rate of change of the hazard curves between the SCR and the New Zealand ATR sites is more clearly expressed, with the hazard for a typical Australian site increasing at a much faster rate at low probabilities (or longer return periods) than typical sites in New Zealand. This is a common feature found in other hazard assessments that consider both SCRs and ATRs [e.g., 68 ] and is a consequence of the increasing influence of lowprobability large earthquakes at longer return periods.
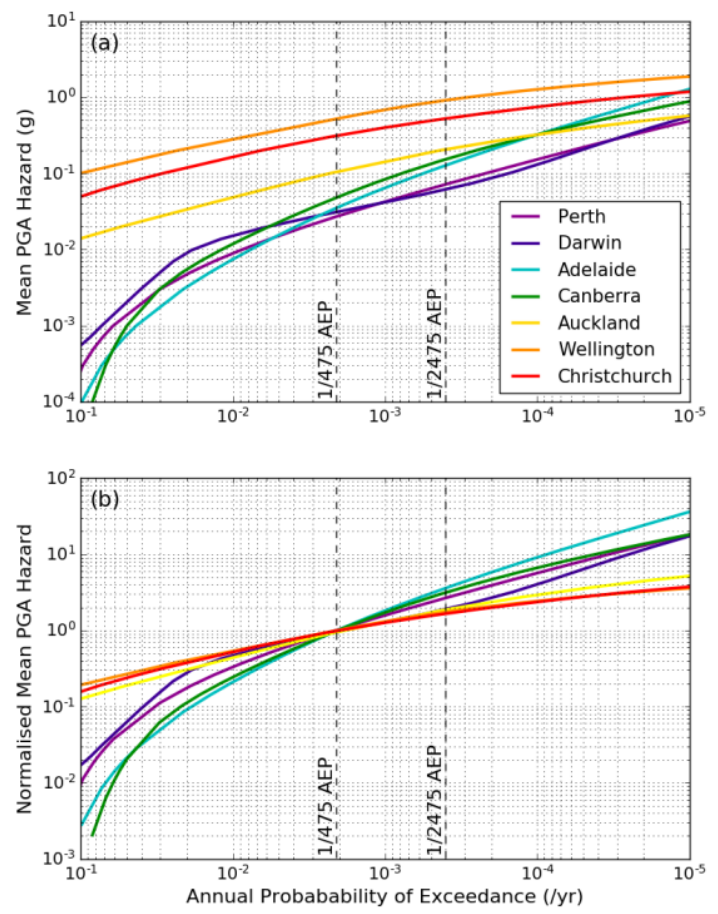

Figure 3: Top panel (a) show NSHA18 PGA hazard curves for representative Australian (Perth, Darwin, Adelaide and Canberra) and New Zealand (Auckland, Wellington and Christchurch) cities. Bottom panel (b) shows the same hazard curves normalised at the 1/475 AEP to emphasise rate of change of hazard curves between Australian (SCR) and New Zealand (ATR) localities.

While the current design probability in Australia for ordinaryuse structures is $1 / 500 \mathrm{AEP}$, it is necessary to scale seismic hazard to different ground-motion return periods for the design of high-importance structures, in particular. In the AS1170.42007, this is achieved using the probability factor $\left(k_{p}\right)$, equivalent to the return period factor $R_{S}$ or $R_{U}$ in the NZS 1170.5-2004 [69]. The $k_{p}$ factor is calculated by normalising the hazard curve by its value at a recurrence interval of 500 years. The AS1170.4-2007 uses the same factors for PGA as defined in the NZS 1170.5-2004 and derived by McVerry [70] for a spectral period of $S a[0.5 \mathrm{~s}]$. Thus, the AS1170.4-2007 assumes that PGA in Australia scales with return period similarly to $S a[0.5 \mathrm{~s}]$ for average sites in New Zealand. As with the 2012 National Seismic Hazard Maps [NSHM12; 71, 72], the $k_{p}$ factors derived from the NSHA18 for the PGA intensity measure differ markedly from those factors given in the current Standard, with a national average of $k_{p}=3.15$ at the $1 / 2500$ AEP, compared to $k_{p}=1.8$ in the AS1170.4-2007. The use of the NSHA18-derived $k_{p}$ factors, on average, would represent an increase in hazard scaling from $1 / 500$ to $1 / 2500$ AEP of approximately $75 \%$ relative to the current AS1170.4-2007 factors. 
Figure 4 shows the comparison of $k_{p}$ factors for the eight capital cities across Australia. It is clear that there is a large variation in the $k_{p}$ factors among these localities. Differences in $k_{p}$ factors between localities expresses the difference in the shape of the seismic hazard curve (e.g., Figure 3). In seismically active regions, moderate-to-high level ground shaking has a higher chance of being exceeded than in SCRs. Additionally, sites in SCRs with low 1/500 AEP hazard will start from a lower base hazard level (e.g., Brisbane). Consequently, $k_{p}$ factors will rise more rapidly when rarer events occur because the 1/500 hazard levels will be more easily exceeded over longer return periods. However, this explanation does not hold true for sites affected by seismogenic faults, such as Adelaide. The $k_{p}$ factors for Adelaide are among the highest because of the nearby fault sources, which do not contribute significantly to the hazard at the 1/500 AEP due to their estimated long recurrence intervals [55]. However, these fault sources will tend to contribute proportionately more to seismic hazard at higher return periods, as is demonstrated for the $k_{p}$ curve for Adelaide.

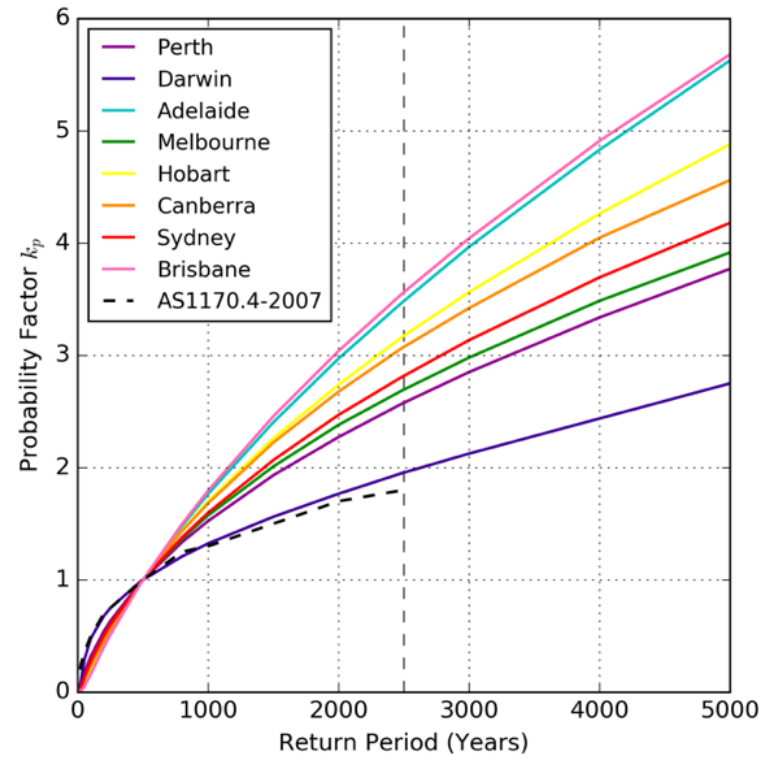

Figure 4: The PGA probability factor $\left(k_{p}\right)$ for the eight capital cities compared to the $k_{p}$ values in AS1170.4-2007. The factors are calibrated such that $k_{p}=1.0$ for a 1/500 AEP. The thin vertical dashed line indicates a groundmotion return period with an annual exceedance probability of $1 / 2500$.

The $k_{p}$ curve for Darwin appears to mimic the factors in the AS1170.4-2007, which were derived from the factors determined for tectonically active New Zealand [69]. The dominant sources of hazard for Darwin are the plate margin earthquakes off northern Australia [i.e., 27]. Because these sources occur in ATRs, northern Australian sites are likely to exceeded moderate levels of ground shaking with shorter return intervals. Consequently, the hazard increase for lower probabilities of exceedance for Darwin occurs at a slower rate relative to typical SCR sites, where the hazard contribution of large rare earthquakes leads to faster increases in seismic hazard for decreasing probabilities of occurrence [e.g., 68, 73]. It is also worth noting that variability in the $k_{p}$ factor (or return period factor, $R_{S}$ ) is also noted between sites in New Zealand $[70,74]$. This suggests the need for site-specific hazard scaling for different return periods for future seismic design provisions, not just in Australia, but in New Zealand as well.

On a final note, the term "return-period," commonly used in building codes is, to some extent, misleading because it implies regularity of recurrence for seismic events, which contradicts the time-memoryless Poisson process upon which earthquake rate models are based [2].

\section{Uniform Hazard Spectra}

In the AS1170.4, the spectral shape factors translate the seismic hazard factor (anchored at PGA or $\mathrm{Sa}[0.0 \mathrm{~s}]$ ) to an elastic design spectrum [e.g., 75]. This spectrum can be used to determine the period-dependent design values at the fundamental period of interest. This general approach allows design provisions to be determined for structures with different fundamental periods in many seismic design codes around the world. However, it is noted that the definition of these spectral shape factors often provides a poor approximation for, in particular, long-period displacement spectra [76]. While the shape of the elastic response spectrum can change with seismic site class [e.g., 9, $75]$, design codes usually do not make provision for changes in the shape of the elastic design spectrum owing to earthquakes occurring in different tectonic region types with different rupture styles, predominant earthquake magnitude, source-tosite distance [76] and even for different AEPs [77]. As a consequence, the standard spectral shape factors will often not deliver uniform hazard or risk across all oscillation periods [78]. The AS1170.4-2007 introduced some conservatism in displacement-based demands through the adoption of a constant displacement from a second corner period $\left(T_{2}\right)$ in the design spectrum at $1.5 \mathrm{~s}$ [75]. Many international standards now require long-period spectral ordinates (up to $10 \mathrm{~s}$ ) for the seismic design of large long-span structures [e.g., Canadian Highway Bridge Design Code, CSA S6-14; 79]. Should this be a future requirement for Australia, the shape of long-period design spectrum may need to be revisited.

In Australia, it is recognised that the calculated uniform hazard spectrum (UHS) results in different spectral shapes for different locations across the continent $[8,72]$. A common UHS among all sites is not possible because the seismic hazard at one site is influenced by earthquakes of different magnitude at different distances - as modelled through PSHA - and these will contribute differently to the shape of the UHS [e.g., 74]. This is underscored by the UHS for the city of Darwin (Figure 5), calculated for 11 response spectral periods from $T=0.0 \mathrm{~s}$ (or PGA) to $4.0 \mathrm{~s}$. The risk of strong earthquake ground motions from local earthquakes near Darwin is relatively low given the low seismicity rates from known nearby seismic sources. Additionally, smaller earthquakes at near-field distances will tend to contribute more ground-motion hazard at shorter oscillation periods. However, given northern Australia's proximity to the active tectonic-plate boundary in the Timor Trough-Banda Sea region, frequent large earthquakes occur and many of these are felt in Darwin [43, 44]. Most recently a $M_{W} 7.3$ earthquake on 24 June 2019 caused minor damage in the city and has led to a number of insurance claims [80]. Figure 6 shows the geographic deaggregation of the long-period seismic hazard [81] estimated in Darwin from these far-field sources based on the NSHA18 seismic source and groundmotion characterisations. These large distant earthquakes contribute significantly to long-period hazard in the UHS because the long-period ground motions propagate more efficiently over large distances, particularly through old continental crust of the North Australian Craton [46]. Based on Figure 5, the use of standard elastic design spectrum to determine design ground motions for long-period structures (such as bridges and dams) in northern Australia may lead to the assignment of non-conservative design motions.

The current International Building Code (IBC), developed in the United States (US), uses the risk-targeted maximum considered earthquake (MCER) hazard calculated at periods of $0.2 \mathrm{~s}\left(S_{S}\right)$ and $1.0 \mathrm{~s}\left(S_{1}\right)$ to define the design spectrum [e.g., 82]. 
However, this approach is only appropriate if the peak MCER response spectral acceleration occurs near $0.2 \mathrm{~s}$ and the peak response spectral velocity occurs near $1.0 \mathrm{~s}$ for the site of interest [83]. The type of event that dominates hazard (i.e. crustal, subduction interface, subduction intraslab, etc) may also have a bearing on the spectral shape [e.g., 84]. Consequently, defining the design spectrum based only on two spectral periods will potentially be non-conservative if these criteria are not met. For this reason, coupled with dependence of the UHS shape based on a site's location relative to different earthquake sources, the use of a full UHS over the range of oscillation periods is recommended to determine design spectra for future editions of the AS1170.4. This approach is also now being adopted by the $I B C$ [e.g., 85$]$.

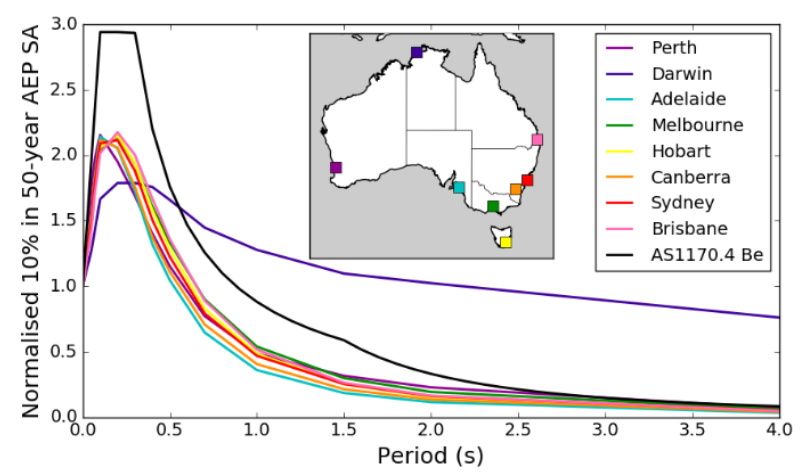

Figure 5: Normalised 1/500 AEP UHS on Site Class Be for several capital cities from the NSHA18 (see inset for location), showing the distinctive long-period behaviour for Darwin due to plate-boundary earthquakes north of Australia. The respective AS1170.4-2007 spectral shape factors anchored to the respective $Z$ values are also shown.

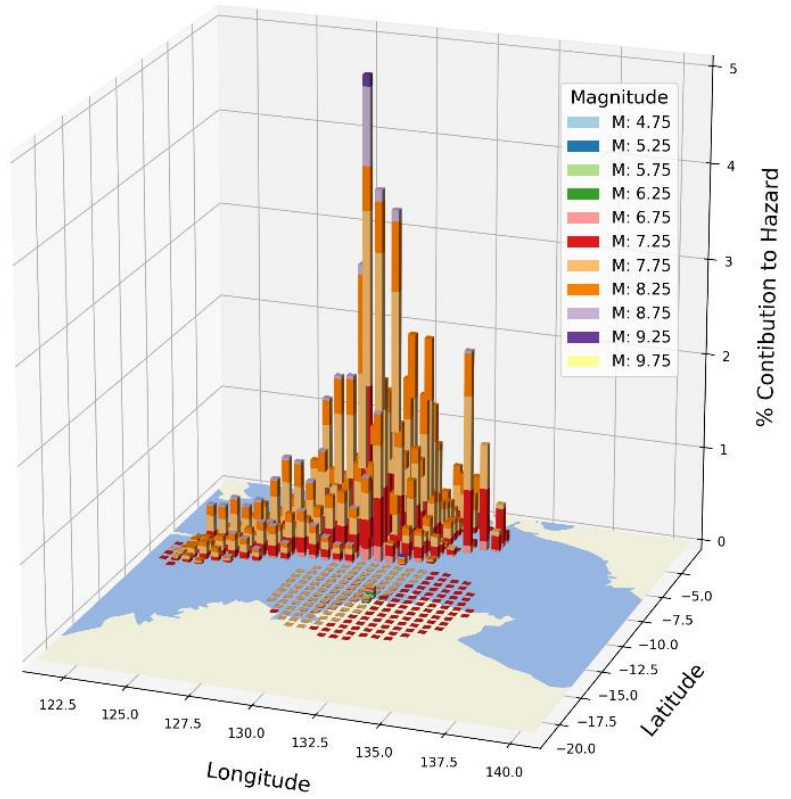

Figure 6: Geographic deaggregation for Darwin SA(2.0 s) for a probability of $2 \%$ probability of exceedance in 50 years showing the estimated influence of Australia's northern plate margin sources on long-period seismic hazard. The deaggreation shows the location and magnitudes of the seismic sources that contribute to the overall seismic hazard.

\section{Site Class Factors}

In the AS1170.4-2007, the site classification scheme is similar to that initially proposed by the National Earthquake Hazard Reduction Program [NEHRP; 86]. However, the AS1170.4 uses a site's natural period $(T s)$ as an additional criterion for classification [75]. The site amplification factors, embedded within the spectral shape factors (Standards Australia, 2007), are based on average short- and mid-period amplifications $\left(F_{a}\right.$ and $F_{v}$, respectively) with respect to the reference ground condition [e.g., 87].

The understandings of ground-motion amplification have evolved considerably since the mid-1990s with most GMMs now explicitly considering period-dependent amplifications from the effects of near-surface geology and basin amplifications. The augmentation of empirical ground-motion datasets with more abundant data across more diverse site conditions has, to a large degree, facilitated these advancements [e.g., 88].

Figure 7 shows a comparison of the AS1170.4-2007 amplification factors, anchored to Site Class Be [9], relative to modern period-dependent amplification factors developed through the Next Generation Attenuation (NGA) - West 2 project [88]. The mapping between NEHRP and AS1170.4 site classes used in this study is shown in Table 1. Unlike amplification factors implicit within most modern GMMs, the factors used in the AS1170.4-2007 are not dependent on ground-motion intensity and appear to be non-conservative for soft-soil sites and low ground motions (where linear amplification is expected) relative to modern amplification models (Figure 7a). However, for stronger ground-motions, the AS1170.4-2007 factors will tend to be conservative and predict stronger amplifications at soil sites owing to expected nonlinear behaviour of modern amplification models for mid-toshort periods, $T<1.0 \mathrm{~s}$ (Figure $7 \mathrm{~b}$ ). The actual ground-motion amplification will vary from site to site and will depend on the shear-wave velocity profile beneath the site. However, a comparison of the current $F a$ and $F v$ amplification factors shows that the modern models of Seyhan and Stewart [88] demonstrate a much smoother transition between short and long-period amplification, as well as an improved consideration of non-linear shaking effects for strong-ground motions.

Whilst more empirical observations exist from which to base modern amplification factors, it is still very difficult for GMM developers to fully decouple wave-path effects from site effects (including effects from basins). Moreover, it has been recognised that amplification factors vary between GMMs, even those with the same reference site condition. The factors also vary between tectonic region types for which the GMMs were derived [89]. Consequently, the use of a single $F_{a}$ and $F_{v}$ amplification model anchored to a particular reference site condition are likely to be inconsistent with the GMMs used in modern probabilistic seismic hazard assessments.

Table 1: Mapping of AS1170.4-2007 and NEHRP Site Class used in this study.

\begin{tabular}{|l|l|l|}
\hline $\begin{array}{c}\text { AS1170.4-2007 Site } \\
\text { Class }\end{array}$ & $\begin{array}{c}\text { Modified NEHRP } \\
\text { Site Class }\end{array}$ & $\begin{array}{c}\text { Reference } \boldsymbol{V}_{\boldsymbol{S 3 0}} \\
(\mathbf{m} / \mathbf{s})\end{array}$ \\
\hline $\mathrm{A}_{\mathrm{e}}$ & B & 1100 \\
\hline $\mathrm{B}_{\mathrm{e}}$ & B/C & 760 \\
\hline $\mathrm{C}_{\mathrm{e}}$ & C & 464 \\
\hline $\mathrm{D}_{\mathrm{e}}$ & $\mathrm{D}$ & 270 \\
\hline $\mathrm{E}_{\mathrm{e}}$ & E & 150 \\
\hline
\end{tabular}

Given this likely disconnect between amplification factors developed for GMMs and the reference site condition in building codes, the National Building Code of Canada (NBCC) is currently calculating seismic design values directly on primary (e.g. A-E) and intermediate (A/B-D/E) seismic site classes using GMM-specific amplification functions [90, 91]. This approach is also being adopted by the US IBC [85]. Thus, 
it is suggested that, for future editions of the AS1170.4, seismic hazard be calculated directly for a given site class using amplification models provided by the developers of each of the GMMs used in the ground-motion logic tree.
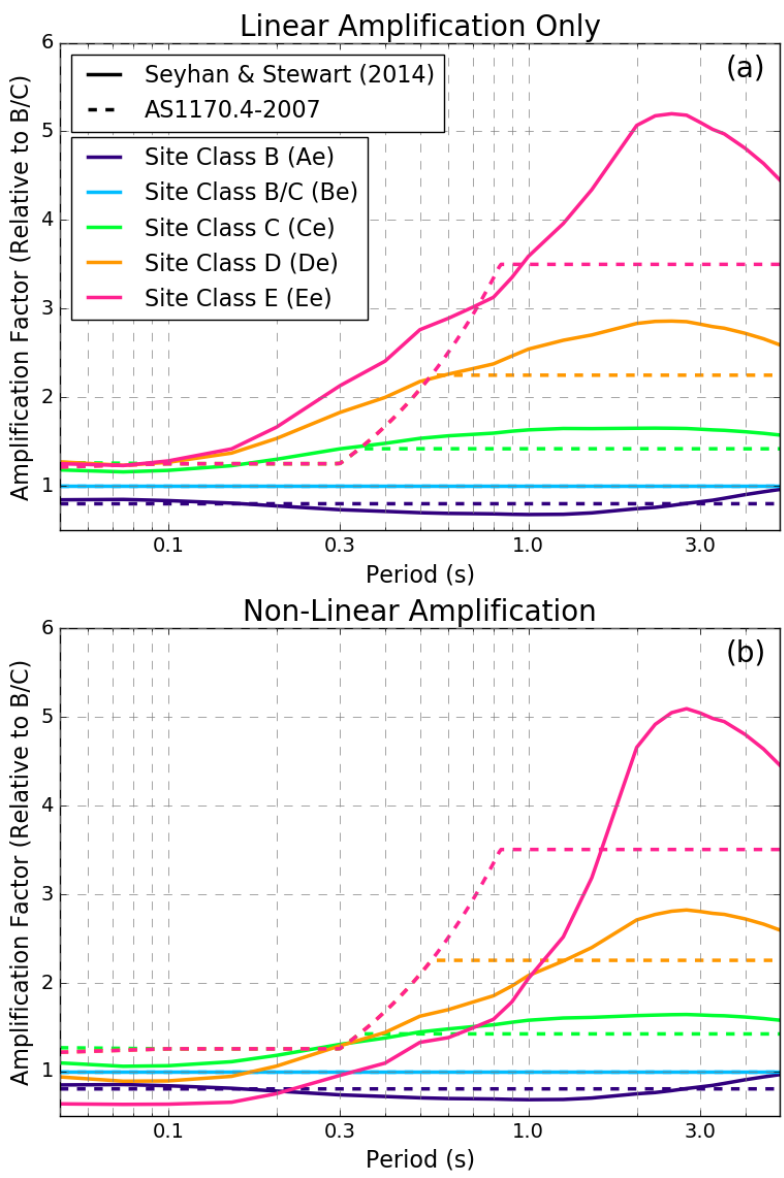

Figure 7: A comparison of the AS1170.4 amplification factors, anchored to an AS1170.4 Site Class Be [9; dashed lines], relative to modern period-dependent amplification factors developed through the NGA - West 2 project [88; soid lines]. The top panel (a) demonstrates the Seyhan and Stewart [88] amplification model using a reference PGA (i.e., PGA ${ }_{\text {ref }}$ of $0.1 \mathrm{~g}$ (i.e., linear amplification), while the bottom pannel (b) shows amplification with non-linear effects considered using a PGA ref of $0.4 \mathrm{~g}$. The AS1170.4 factors are not dependent on ground-motion intensity.

Whilst it would still be incumbent on the user to determine the appropriate site class, the adoption of site-class-specific hazard maps would fundamentally simplify the way end users would determine seismic design values for a given location and site class, but would have other technical advantages. Firstly, with the advances in modelling ground-motion attenuation, GMMs now apply the time-averaged shear-wave velocity in the upper $30 \mathrm{~m}$ of a sites foundation $\left(V_{S 30}\right)$ as a predictive variable, meaning that ground-motions for a given magnitude, distance and site class can now be directly computed within a GMMs functional form. Secondly, the approach considers the epistemic variability among different GMM amplification models, allowing modellers to better quantify the uncertainty of the design ground motions for each site class. Another advantage of directly computing seismic hazard for a predefined site class is that non-linear ground-motion effects are implicitly considered in the probabilistic hazard framework. Finally, GMMs and their coupled amplification functions, developed through regression analysis of potentially disparate datasets, are less dependent on fully decoupling amplification effects (including basin response) from a reference rock site, which is implicitly assumed by amplification factors in most building codes.

The utility of $V_{S 30}$ as a proxy for site class and amplification in some geological environments has been questioned by several researchers [e.g., 92, 93] and this debate should not be dismissed. However, this parameter is now pervasive throughout the published GMMs, and in the absence of a universally accepted alternative, it is the parameter that will be continued to be relied upon for future seismic hazard assessments. Additionally, the geometry and geophysical properties of deep sedimentary basins cannot always be easily defined at a national scale. So whilst some GMMs now have provisions to estimate shaking intensities for sedimentary basins [e.g., 94, 95], they cannot always be applied for nationalscale hazard assessment.

\section{Alternate Ground-Motion Exceedance Probabilities}

The selection of the $10 \%$ exceedance probability in 50 years for the first United States (US) National Seismic Hazard Maps was originally a rather arbitrary decision and appeared to be a "reasonable" choice to ensure structures "remain operable" following large earthquakes [96]. This probability level was generally viewed to be appropriate for the average recurrence of large damaging earthquakes in well-studied ATRs such as California, and was also considered suitable for collapse prevention. Given that this was best practice for the time, this exceedance probability was also adopted by the $N C C$ for use in the first edition of the AS1170.4-1993 [97]

The design probabilities used in building codes are not intended to express zero earthquake risk. Because the PSHA method explicitly allows for the mapped hazard values to be exceeded, it is expected that strong ground shaking will occur where mapped hazard is lower than the seismic demands that may be experienced at any given site [e.g., 98]. In general terms, a 1/500 AEP means that in any 50-year period, we should expect approximately $10 \%$ of the Australian continental landmass to experience shaking exceeding mapped values [e.g., 1, 99, 100]. This exceedance level is approximately equivalent to a fractional area of the continent equivalent to the state of New South Wales. As earthquake scientists and engineers, it is reasonable to ask whether this exceedance probability level is acceptable.

In the late 1990s, concerns were raised by engineers and seismologists in the US that anchoring design hazard values to 1/475 AEP would result in significant disparities in the seismic performance of ordinary-use structures across the country, with regions of low-to-moderate levels of seismicity being considerably more at risk to extreme ground-motion events [e.g., 73, 101, 102]. These concerns led to the adoption of seismic design ground-motion demands for a $2 \%$ probability of exceedance in 50 years $(1 / 2475 \mathrm{AEP})$ for the $I B C$. This change in the exceedance probability level was adopted in the National Building Code of Canada (NBCC) shortly thereafter [103]. The $1 / 2475$ AEP level is thought to more closely relate to the probability of structural collapse for regular structures [76]. Whilst this approach had its critics [104, 105], the adoption of this ground-motion exceedance probability leads to several advantages:

- In low-to-moderate seismicity regions, there is a larger difference between $1 / 475$ and 1/2475 AEP groundmotions than in more tectonically active regions [e.g., 106]. Transitioning to lower exceedance probabilities in the national design provisions reduces the risk in low-tomoderate seismicity regions due to rare extreme ground motions [68]; 
- The rate of attenuation of earthquake ground-shaking is generally lower in stable continental regions (SCRs) like Australia [37, e.g., 107]. Thus, these provisions protect against rare events that have the potential to affect larger areas than in tectonically active regions;

- $\quad$ Structures in low-to-moderate seismicity regions would be designed with more comparable seismic resistance (combined strength and ductility) to structures in high seismicity regions;

- In many cases, effective seismic resistance for new construction can be achieved at minimal incremental cost $[73,108]$.

Australia has much in common in terms of the vintage of urban development and tectonic setting with eastern North America [e.g., 109]. Given that both Canada and the United States have recognised that $10 \%$ probability of exceedance in 50 years does not provide seismic protection to extreme ground motions from rare events in their low-seismicity settings, it would seem sensible that Australia too, should review suitability of the probability levels currently required for ordinary-use structures by the $N C C$. This is underscored by the significant reductions in its seismic hazard forecasts at the 1/500 AEP through the NSHA18 [8].

The updated AS1170.4-2007 (R2018) [64] uses the original AS1170.4-1993 seismic hazard factors, but now requires a minimum design PGA level of $0.08 \mathrm{~g}$. Figure 8 maps the ratio of the NSHA18 1/500 and 1/2475 AEP PGA values relative to the AS1170.4-2007 (R2018) values. These ratios assume the minimum hazard design factor of $Z=0.08 \mathrm{~g}$ as recommended by the $A S 1170.4-2007(R 2018)$ [64]. If we assume a 1/500 AEP is appropriate for design and construction in Australia, a pragmatist might argue that the current provisions are already adequate for all localities (Figure 8a). Therefore, there would be little-to-no risk in not updating the underlying hazard maps with the modern hazard estimates. However, this all depends on whether we, as a community, are comfortable accepting a $10 \%$ in 50-year exceedance level. If the response is "no", and we now compare the existing provisions required for ordinary-use structures with the NSHA18 1/2475 AEP PGA values, we see that there are now several localities where the lower-probability seismic hazard exceeds that of the current design provisions (Figure 8b). Critically, some of these localities include major urban centres of Canberra, Melbourne and Adelaide, as well as strategically important localities such as Morwell in the Latrobe Valley (Victoria) and Port Hedland off the northwest shelf (Western Australia). Therefore, these localities could be vulnerable to ground-motions from extreme events. In line with the AS1170.4-2007 amendment adopted in 2018, minimum base shear design values could apply for the remaining lowhazard jurisdictions should the exceedance probabilities be adjusted [e.g., 110].

The decision to adjust ground-motion exceedance objectives in building codes is not solely a scientific question and should be established through consultation of not only structural engineers and seismic hazard experts, but also community leaders, actuaries, sociologists and other decision makers [e.g., $111,112]$. Another important stakeholder group that is often overlooked is the general public, or those who will live and work within future buildings. This group of people are often unsatisfied when they learn that structures designed to satisfy the "life safety" objective, consistent with existing codes, may have poor seismic resistance when subjected to strong earthquake loading [e.g., 108].

It should be noted that neither Canada nor the United States use the $2 \%$ in 50-year hazard values directly calculated from their national-scale probabilistic hazard assessments for defining the seismic loading for building design, and use methods such as deterministic capping of ground motions for near-fault sites, or $2 / 3$ of the risk-targeted maximum considered earthquake ground motions for assigning design levels [i.e., 68, 113, 114]. Nevertheless, the application of these adjustments would still yield higher seismic loading requirements, relative to the AS1170.4-2007 [9] for many localities across Australia. In summary, any considerations for updating future design provisions in Australia should carefully consider the groundmotion exceedance probability required for ordinary-use structures and whether the design probabilities meet community expectations for seismic safety.

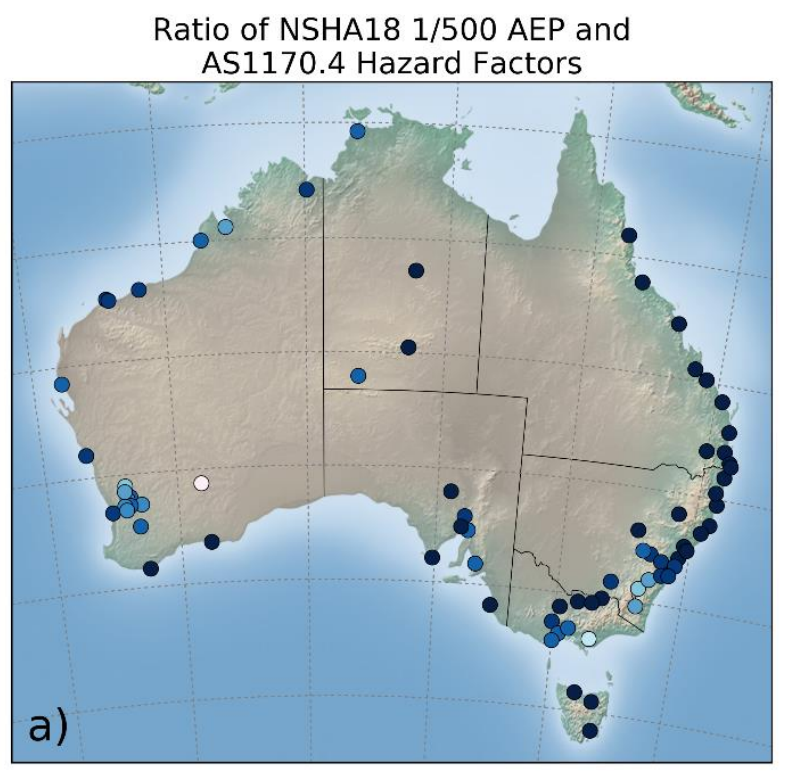

Ratio of NSHA18 1/2475 AEP and AS1170.4 Hazard Factors

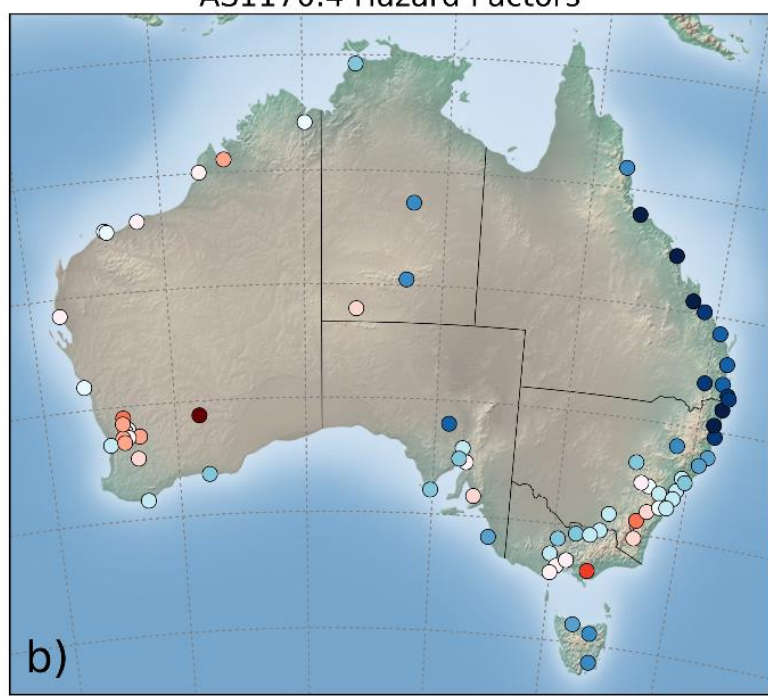

$\begin{array}{lllllllll}0.0 & 0.35 & 0.5 & 0.71 & 1.0 & 1.41 & 2.0 & 2.83 & 4.0\end{array}$ Hazard Ratio (NSHA18 / AS1170.4-2017 [R2108])

Figure 8: Comparison of seismic hazard design factors at AS1170.4 localities illustrating a) the ratio of NSHA18 1/500 $A E P$ PGA relative to the AS1170.4-2007 (R2018) and b) the ratio of NSHA18 1/2475 AEP PGA relative to the AS1170.42007 (R2018) hazard design factors assuming a minimum hazard design factor of $Z=0.08 \mathrm{~g}$. 


\section{Risk-Targeted Ground Motions}

An alternative method to arrive at seismic demands is through risk-targeted ground motions. Traditionally, seismic design codes rely on maps that provide a "constant hazard" assumption where the maximum considered earthquake (MCE) ground motions used for design are those that assume a uniform exceedance probability (e.g., $2 \%$ probability of exceedance in 50 years) that is constant across a region [111]. However, Luco et al. [114] suggested it would be more consistent with the final use of seismic design maps to adopt a "constant risk" assumption in which the design ground motions are defined to provide to a certain level of risk, for example, annual probability of collapse. The $I B C$ has specified so-called risktargeted maximum considered earthquake $\left(\mathrm{MCE}_{\mathrm{R}}\right)$ ground motions for designing new buildings and other structures since 2012. If employed for design purposes, MCER ground motions lead to the same nominal collapse probability, or a uniform level of risk, over the region of concern [112].

Maps that indicate the spatial variability of ground-motion hazard for a uniform exceedance probability still provide the basis for seismic design in most jurisdictions around the world. The decision to design structures to a uniform ground-motion exceedance level assumes a structure would have the same collapse probability in any locality [112]. However, constant hazard ground-motion maps do not necessarily lead to uniform estimates of collapse probabilities due to differences in the rate of change of hazard at different exceedance probabilities (see Figure 3) and uncertainties in collapse capacity (e.g., the acceleration threshold at the structure's fundamental period) for different structures. Thus, the uniform hazard assumption can lead to inequitable risks of collapse over a given time period at different localities. It should be noted that the collapse capacity for any given structure will be sensitive to several factors, such as construction quality, material properties, structural irregularities, etc. [114] and it is important to recognise that this method refers to a typical structure.

Risk-targeted $\mathrm{MCE}_{\mathrm{R}}$ ground motions are based on the "risk integral" [114]. The key ingredients for risk-targeted calculations are:

- mean ground-motion hazard curves that cover a range of exceedance probabilities;

- fragility (or capacity) curves that express the conditional probability of failure at a ground motion level, and;

- a pre-defined uniform collapse risk objective, or the probability of collapse (e.g., $1 \%$ in 50 years).

The integral takes into account the mean hazard curve across a range of exceedance probabilities rather than simply basing the design ground motions on a single spectral acceleration for a pre-defined return period [111]. Consequently, the relative slopes of the hazard curves for each site can have a significant impact on the $\mathrm{MCE}_{\mathrm{R}}$ ground motions. Incorporating uncertainty into the fragility curve is necessary because of variability in the performance of structures due to differences in their aforementioned construction characteristics [e.g., 114]. Fragility curves commonly adopt a lognormal distribution, defined by a mean and standard deviation.

The evaluation of this integral requires that the acceptable risk to society be quantified. Again, this is not solely a scientific question and it should be established through the consultation of a wide cross-section of stakeholders [e.g., 111, 112]. In the US, it was determined by structural engineers that a uniform national collapse risk of $1 \%$ in 50 years (about $2 \times 10^{-4}$ per annum) is an acceptable threshold for use in the $I B C$.

Allen and Luco [106] explored the use of the risk-targeted hazard approach for Australian localities based on the NSHA18 calculations. The PGA MCER ground motions for Australian localities typically leads to an average hazard reduction factor (or "risk coefficient") of 0.94 relative to MCE ground motions [106]. Risk coefficients of this order are consistent with the $\mathrm{MCE}_{R}$ ground motions in the U.S. design maps [82]. Nevertheless, it is worth noting that the use of the MCE approach using a target collapse risk of $1 \%$ in 50 years will provide more conservative (i.e., higher) design ground motions at most localities than would be achieved by using the NSHA18 $1 / 500$ AEP values [106]. This is because the values are not preconditioned on the choice of a constant hazard objective, but rather a constant risk objective. Ultimately, the decision to adopt $\mathrm{MCE}_{\mathrm{R}}$ ground motions for future editions of the $A S 1170.4$, and at what risk level, should be based on broad community consultation.

\section{FINAL REFLECTIONS}

This contribution discusses some of the challenges facing seismic hazard analysis in regions of low seismicity, with emphasis on the Australian continental setting. Oftentimes, criticisms are misdirected at the PSHA method when, in fact, assumptions made during the model-building process are often at the heart of the problem [2, 98, 115]. Whilst PSHA aims to forecast seismic hazard in terms of a ground motion intensity for a given exceedance probability, this can only be achieved with sufficient knowledge on the behaviour of past events, both historic and neotectonic. As our understanding of earthquake occurrences and their ground-motion effects improve (and their respective uncertainties reduced), so too will the reliability and stability in our seismic hazard forecasts [e.g., 116].

Particular challenges for improving the robustness of seismic hazard assessments in regions of low seismicity include the completeness and quality earthquake catalogues, groundmotion and seismic-source model characterisation, and their influence on seismic hazard estimates. While many of these challenges will require ongoing monitoring and research, there are several opportunities to improve seismic hazard estimation by utilising existing datasets and methods. However, philosophical challenges will remain in terms of how to best model seismic hazard at different spatial scales for varying exceedance probabilities of interest. In the face of these challenges and uncertainties, there remain opportunities to advance earthquake hazard science for SCRs, such as Australia. This will ultimately improve the seismic safety of our communities and protect our major infrastructure assets.

From the perspective of engineering design, several opportunities to modernise the manner in which seismic demands are considered in Australian building design for future editions of the AS1170.4 have been explored. While the NSHA18 estimates of hazard have generally decreased on the national scale at the $1 / 500 \mathrm{AEP}$, there are some localities where the $A S 1170.4-2007$ (R2018) may underestimate earthquake risk at some key localities relative to the NSHA18, if the $1 / 2475$ AEP were deemed to be a more appropriate design objective. The challenge for the Australian earthquake engineering and seismology communities, in addition to other community leaders in consultation with the public, is to determine whether we are comfortable accepting a 1/500 AEP where these design levels may not be currently providing adequate seismic protection for potential MCE ground-motions in some major urban centres.

Alternatively, rather than modifying the ground-motion exceedance probabilities using a "constant hazard" assumption, the AS1170.4 could move towards ground-motion design values that target a uniform collapse probability. Benefits of using the so-called risk-targeted MCER ground motions include the explicit consideration of whole hazard curves across a range of 
exceedance probabilities, quantification of collapse prevention objectives and mainstreaming the notion of collapse risk into earthquake engineering practice. Alternative approaches have recently emerged that redefine societal risk in terms of tolerable mortality rate as a performance objective in structural design codes [i.e., 117], warranting further consideration in mitigating the societal impacts of earthquakes.

We return now to the original question posed in the manuscript's title; does PSHA meet the needs for modern engineering design in Australia? The answer to this question may be contentious and will depend on the perspectives of the individual [e.g., 10]. However, in the author's opinion, yes, it does. PSHA is currently the best method we have to provide evidence-based forecasts on the likely ground-shaking intensities that may affect a locality within the Australian continental setting.

However, end-users of PSHAs must also recognise the uncertainties associated with the method, often driven by limitations in data and knowledge. These epistemic uncertainties in PSHA are commonly considered and quantified through a weighted logic-tree framework that considers alternative model branches [e.g., 52, 118]. The improved characterisation of modelling uncertainties provides additional information regarding the utility and confidence of seismic hazard assessments for end users.

Whilst PSHA in Australia is an imprecise science and will continue to have considerable uncertainties into the future, these uncertainties will diminish over time as the science underpinning the component input models improves. Additionally, the PSHA framework enables hazard practitioners to include multiple sources of modelled uncertainty and to propagate these through to the final (mean) hazard result. It is becoming increasingly important to communicate the mean hazard results from PSHAs in the context of their uncertainties [e.g., 4, 5], ensuring that hazard assessments are both transparent and defensible to end users and the wider seismological and earthquake engineering communities $[119,120]$. However, it is also important that the right questions are being asked of hazard modellers in terms of the provision of seismic demand objectives that are fit for purpose in the design and construction of resilient communities into the future.

The opportunities to update earthquake loading provisions presented herein use modern approaches and models and follow global best practices and evidence-based science for determining seismic demands at a given site. Whilst the current AS1170.4 (and its requisite exceedance probability) still prescribes conservative seismic design for much of Australia relative to the NSHA18 results, this paper suggests that there are potentially some key localities across the continent where the current standards may be non-conservative if an alternative hazard (or risk) objective was applied. Therefore, there is strong rationale to support the use of these alternative objectives to mitigate earthquake risk in regions with low seismicity [e.g., 68]. Consequently, constructive discussions among Standard Australia's Technical Subcommittee, hazard practitioners and end users are suggested to consider alternative hazard and/or risk objectives for future editions of the AS1170.4.

\section{ACKNOWLEDGEMENTS}

This is an updated and extended version of a paper presented at the Eleventh Pacific Conference on Earthquake Engineering (PCEE) at Auckland in April 2019. The author would like to acknowledge the various contributions to the content of this paper through conversations with the NSHA18 team at Geoscience Australia (Jonathan Griffin, Mark Leonard, Dan Clark and Hadi Ghasemi). Discussions with Tuna Onur and
Nicholas Luco have been helpful in framing this discussion. Joanne Stephenson is thanked for producing Figure 6. Elizabeth Abbott and Matt Gerstenberger are thanked for supplying seismic hazard information for key localities in New Zealand. Martin Wehner, Mark Edwards, Dan Clark, Jane Sexton and Hadi Ghasemi have provided useful feedback on previous versions of this manuscript. An anonymous reviewer is also thanked for their thoughtful comments and suggestions. Finally, this manuscript is published with the permission of the CEO of Geoscience Australia (eCat: 131217).

\section{REFERENCES}

1 Vanneste K, Stein S, Camelbeeck T and Vleminckx B (2018). "Insights into earthquake hazard map performance from shaking history simulations". Sci. Rep., 8: 1855, doi: 10.1038/s41598-018-20214-6.

2 Gerstenberger MC, Marzocchi W, Allen T, Pagani M, Adams J, Danciu L, Field E, Fujiwara H, Luco N, Ma KF, Meletti C and Petersen M (2020). "Probabilistic seismic hazard analysis at regional and national scale: state of the art and future challenges". Rev. Geophys., doi: 10.1029/2019RG000653R.

3 Pagani M, Monelli D, Weatherill G, Danciu L, Crowley H, Silva V, Henshaw P, Butler R, Nastasi M, Panzeri L, Simionato M and Vigano D (2014). "OpenQuake Engine: An open hazard (and risk) software for the Global Earthquake Model". Seism. Res. Lett., 85(3): 692-702, doi: 10.1785/0220130087.

4 Lee Y, Graf W and Hu Z (2018). "Characterizing the epistemic uncertainty in the USGS 2014 National Seismic Hazard Mapping Project (NSHMP) ". Bull. Seism. Soc. Am., 108(3A): 1465-1480, doi: 10.1785/0120170338.

5 Allen TI, Griffin JD, Leonard M and, Clark DJ, Ghasemi H (2020). "The 2018 National Seismic Hazard Assessment of Australia: quantifying hazard changes and model uncertainties". Earthq. Spectra, doi: 10.1193/031319EQS057M.

6 Gutenberg B and Richter CF (1944). "Frequency of earthquakes in California". Bull. Seism. Soc. Am., 34(4): 185-188.

7 Ghasemi H and Allen TI (2018). "Selection and ranking of ground-motion models for the 2018 National Seismic Hazard Assessment of Australia: summary of groundmotion data, methodology and outcomes". Geoscience Australia Record 2018/29, Canberra, pp. 29, doi: 10.11636/Record.2018.029.

8 Allen T, Griffin J, Leonard M, Clark D and Ghasemi H (2018). "The 2018 National Seismic Hazard Assessment for Australia: model overview". Geoscience Australia Record 2018/27, Canberra, pp. 126, doi: 10.11636/Record.2018.027.

9 Standards Australia (2007). "Structural design actions, part 4: Earthquake actions in Australia". Standards Australia AS 1170.4-2007, Sydney, NSW, pp. 52.

10 McCue K (2019). "A comparison of earthquake hazard modelled results". Australian Earthquake Engineering Society 2019 Conference, Newcastle, New South Wales.

11 Australian Building Codes Board (2016). "National Construction Code of Australia: Volume One Amendment 1". Australian Building Codes Board.

12 Clark D and Leonard M (2014). "Regional variations in neotectonic fault behaviour in Australia, as they pertain to the seismic hazard in capital cities". Australian Earthquake Engineering Society 2014 Conference, Lorne, Victoria.

13 Clark D and Allen T (2018). "What have we learnt of cratonic earthquakes in the fifty years since Meckering?". 
Australian Earthquake Engineering Society 2018 Conference, Perth, Western Australia.

14 Clark D, Brennand S, Brenn G, Allen TI, Garthwaite MC and Standen S (2019). "Surface deformation relating to the 2018 Lake Muir earthquake sequence, south west Western Australia: insights into the behaviour of Australian SCR earthquakes". Solid Earth, doi: 10.5194/se-2019-125.

15 Griffin J, Volti T, Clark D and Ghasemi H, Leonard M, Allen T (2016). "Development of the 2018 Australian National Seismic Hazard Assessment (NSHA)". Australian Earthquake Engineering Society 2016 Conference, Melbourne, Victoria.

16 Somerville, Quijada P, Thio HK, Sandiford M and Quigley M (2008). "Contribution of identified active faults to near fault seismic hazard in the Flinders Ranges". Australian Earthquake Engineering 2008 Conference, Ballarat, Victoria.

17 Clark D, McPherson A and Van Dissen R (2012). "Longterm behaviour of Australian stable continental region (SCR) faults". Tectonophys., 566-567: 1-30, doi: 10.1016/j.tecto.2012.07.004.

18 Clark D, McPherson A, Cupper M, Collins CDN and Nelson G (2015). "The Cadell Fault, southeastern Australia: a record of temporally clustered morphogenic seismicity in a low-strain intraplate region". in: A Landgraf, S. Kübler, E. Hintersberger, S. Stein (Eds.) Seismicity, fault rupture and earthquake hazards in slowly deforming regions, Geological Society, London, Special Publications, 163-185, doi: 10.1144/SP432.2.

19 Griffin JD, Stirling MW, Wang T and Clark D (2019). "Towards time-dependent modelling of episodic earthquake occurrence on intraplate faults". Seism. Res. Lett., 90(2B): 895-896.

20 Taylor-Silva BI, Stirling MW, Litchfield NJ, Griffin JD, van den Berg EJ and Wang N (2019). "Paleoseismology of the Akatore Fault, Otago, New Zealand". New Zeal. J. Geol. Geop., doi: 10.1080/00288306.2019.1645706.

21 Leonard M (2008). "One hundred years of earthquake recording in Australia". Bull. Seism. Soc. Am., 98(3): 1458-1470, doi: 10.1785/0120050193.

22 Griffin J, Weatherill G and Allen T (2017). "Performance of national scale smoothed seismicity estimates of earthquake activity rates". Australian Earthquake Engineering Society 2017 Conference, Canberra, ACT.

23 Richter CF (1935). "An instrumental earthquake magnitude scale". Bull. Seism. Soc. Am., 25(1): 1-32.

24 Michael-Leiba M and Malafant K (1992). "A new local magnitude scale for southeastern Australia". BMR J. Aust. Geol. Geophys., 13(3): 201-205.

25 Allen TI (2010). "The influence of attenuation in earthquake ground-motion and magnitude estimation: implications for Australian earthquake hazard". Australian Earthquake Engineering Society 2010 Conference, Perth, Western Australia.

26 Allen TI, Leonard M, Ghasemi H and Gibson G (2018). "The 2018 National Seismic Hazard Assessment for Australia: earthquake epicentre catalogue". Geoscience Australia Record 2018/30, Canberra, pp. 51, doi: 10.11636/Record.2018.030.

27 Griffin J and Davies G (2018). "Earthquake sources of the Australian plate margin: revised models for the 2018 national tsunami and earthquake hazard assessments". Geoscience Australia Record 2018/31, Canberra, pp. 37, doi: 10.11636/Record.2018.031.
28 Bommer JJ and Abrahamson NA (2006). "Why do modern probabilistic seismic-hazard analyses often lead to increased hazard estimates?". Bull. Seism. Soc. Am., 96(6): 1967-1977, doi: 10.1785/0120060043.

29 Al Atik L, Abrahamson N, Bommer JJ, Scherbaum F, Cotton F and Kuehn N (2010). "The variability of groundmotion prediction models and its components". Seism. Res. Lett., 81(5): 794-801, doi: 10.1785/gssrl.81.5.794.

30 Atkinson GM and Boore DM (2006). "Earthquake groundmotion prediction equations for eastern North America". Bull. Seism. Soc. Am., 96: 2181-2205, doi: 10.1785/0120050245

31 Liang JZ, Hao H, Gaull BA and Sinadinovski C (2008). "Estimation of strong ground motions in southwest Western Australia with a combined Green's function and stochastic approach". J. Earthq. Eng., 12(3): 382-405, doi: 10.1080/13632460701568607.

32 Allen TI (2012). "Stochastic ground-motion prediction equations for southeastern Australian earthquakes using updated source and attenuation parameters". Geoscience Australia Record 2012/69, Canberra, pp. 55.

33 Somerville P, Graves R, Collins N, Song S-G, Ni S and Cummins P (2009). "Source and ground motion models for Australian earthquakes". Australian Earthquake Engineering Society 2009 Conference, Newcastle, New South Wales.

34 Allen TI, Cummins PR, Dhu T and Schneider JF (2007). "Attenuation of ground-motion spectral amplitudes in southeastern Australia". Bull. Seism. Soc. Am., 97(4): 1279-1292, doi: 10.1785/0120060172.

35 Douglas J (2018). "Ground motion prediction equations 1964-2018". Department of Civil and Environmental Engineering, University of Strathclyde July 2018, pp. 624.

36 Goulet C, Bozorgnia Y, Abrahamson N, Kuehn N, Al Atik L, Youngs R, Graves R and Atkinson G (2018). "Central and eastern North America ground-motion characterization: NGA-East final report". Pacific Earthquake Engineering Research Center PEER Report No. 2018/08, University of California, Berkeley, California.

37 Bakun WH and McGarr A (2002). "Differences in attenuation among the stable continental regions". Geophys. Res. Lett., 29(23): 2121, doi:2110.1029/2002GL015457.

38 Allen TI and Atkinson GM (2007). "Comparison of earthquake source spectra and attenuation in eastern North America and southeastern Australia". Bull. Seism. Soc. Am., 97(4): 1350-1354, doi: 10.1785/0120060206

39 Scherbaum F, Delavaud E and Riggelsen C (2009). "Model selection in seismic hazard analysis: an informationtheoretic perspective". Bull. Seism. Soc. Am., 99(6): 3234 3247, doi: 10.1785/0120080347.

40 Somerville P and Ni S (2010). "Contrast in seismic wave propagation and ground motion models between cratonic and other regions of Australia". Australian Earthquake Engineering Society 2010 Conference, Perth, Western Australia.

41 Drummond BJ, Goleby BR and Swager CP (2000). "Crustal signature of Late Archaean tectonic episodes in the Yilgarn craton, Western Australia: evidence from deep seismic sounding". Tectonophys., 329: 193-221.

42 Denham D, Alexander LG and Worotnicki G (1980). "The stress field near the sites of the Meckering (1968) and Calingiri (1970) earthquakes, Western Australia". Tectonophys., 67: 283-317. 
43 Hearn SJ and Webb JP (1984). "Continental-scale felt effects of the large Banda Sea earthquake of 4 November 1963". Bull. Seism. Soc. Am., 74(1): 349-351.

44 McCue K (2013). "Darwin Northern Territory - an earthquake hazard". Australian Earthquake Engineering Society 2013 Conference, Hobart, Tasmania.

45 Ghofrani H and Atkinson GM (2011). "Forearc versus backarc attenuation of earthquake ground motion". Bull. Seism. Soc. Am., 101(6): 3032-3045, doi: 10.1785/0120110067.

46 Fishwick S, Kennett BLN and Reading AM (2005) "Contrasts in lithospheric structure within the Australian craton-insights from surface wave tomography". Earth Planet. Sci. Lett., 231: 163- 176, doi: 10.1016/j.epsl.2005.01.009.

47 Wei Z, Kennett BLN and Zhao L-F (2017). "Lg-wave attenuation in the Australian crust". Tectonophys., 717: 413-424, doi: 10.1016/j.tecto.2017.08.022.

48 Kennett BLN and Furumura T (2008). "Stochastic waveguide in the lithosphere: Indonesian subduction zone to Australian craton". Geophys. J. Int., 172: 363-382, doi: 10.1111/j.1365-246X.2007.03647.x.

49 Allen T, Clark D, Lawrie S, Brenn G, Dimech J, Garthwaite M, Glanville H, Kemp T, Lintvelt C, Lumley D, Pejic T, Sayin E and Standen S (2019). "The 2018 Lake Muir earthquakes: Australia's ninth surface rupturing earthquake sequence in 50 years". Seism. Res. Lett., 90(2B): 951.

50 Van Houtte C, Bannister S, Holden C, Bourguignon S and McVerry G (2017). "The New Zealand Strong Motion Database". Bull. New Zeal. Soc. Earthq. Eng., 50(1): 1-20, doi: 10.5459/bnzsee.50.1.1-20.

51 Kaiser A, Van Houtte C, Perrin N, Wotherspoon L and McVerry G (2017). "Site characterisation of GeoNet stations for the New Zealand Strong Motion Database". Bull. New Zeal. Soc. Earthq. Eng., 50(1): 39-49, doi: 10.5459/bnzsee.50.1.39-49

52 Bommer JJ (2012). "Challenges of building logic trees for probabilistic seismic hazard analysis". Earthq. Spectra, 28(4): 1723-1735, doi: 10.1193/1.4000079.

53 Leonard M, Burbidge DR, Allen TI, Robinson DJ, McPherson A, Clark D and Collins CDN (2014). "The challenges of probabilistic seismic-hazard assessment in stable continental interiors: an Australian example". Bull. Seism. Soc. Am., 104(6): 3008-3028, doi: 10.1785/0120130248.

54 Frankel A (1995). "Mapping seismic hazard in the central and eastern United States". Seism. Res. Lett., 66(4): 8-21, doi: $10.1785 / g s s r l .66 .4 .8$.

55 Clark D, Leonard M, Griffin J, Stirling M and Volti T (2016). "Incorporating fault sources into the Australian National Seismic Hazard Assessment (NSHA) 2018". Australian Earthquake Engineering Society 2016 Conference, Melbourne, Victoria.

56 Allen T, Griffin J and Clark D (2018). "The 2018 National Seismic Hazard Assessment for Australia: model input files". Geoscience Australia Record 2018/32, Canberra, pp. 32, doi: 10.11636/Record.2018.032.

57 Quigley MC, Cupper ML and Sandiford M (2006). "Quaternary faults of south-central Australia: palaeoseismicity, slip rates and origin". Aust. J. Earth. Sci., 53: 285 - 301, doi: 10.1080/08120090500499271.

58 Clark D, McPherson A and Collins CDN (2011). "Australia's seismogenic neotectonic record: a case for heterogeneous intraplate deformation". Geoscience Australia Record 2011/11, Canberra.
59 Griffin J, Gerstenberger M, Allen T, Clark D, Cummins P, Cuthbertson R, Dimas V-A, Gibson G, Ghasemi H, Hoult R, Lam N, Leonard M, Mote T, Quigley M, Somerville P, Sinadinovski C, Stirling M and Venkatesan S (2018). "Expert elicitation of model parameters for the 2018 National Seismic Hazard Assessment: Summary of workshop, methodology and outcomes". Geoscience Australia Record 2018/28, Canberra, pp. 74, doi: 10.11636/Record.2018.028.

60 Griffin JD, Allen TI and Gerstenberger MC (2020). "Seismic hazard assessment in Australia: can structured expert elicitation achieve consensus in the "land of the fair go'?". Seism. Res. Lett., doi: 10.1785/0220190186.

61 Leonard M, McPherson A and Clark D (2012). "Source zonation". in: D.R. Burbidge (Ed.) The 2012 Australian Earthquake Hazard Map, 27-43.

62 Jones TD, Gibson G, McCue KF, Denham D, Gregson PJ and Bowman JR (1991). "Three large intraplate earthquakes near Tennant Creek, Northern Territory, on 22 January 1988". BMR J. Aust. Geol. Geophys., 12: 339-343.

63 Woessner J, Danciu L, Giardini D, Crowley H, Cotton F, Grünthal G, Valensise G, Arvidsson R, Basili R, Betül Demircioglu M, Hiemer S, Meletti C, Musson RW, Rovida AN, Sesetyan K, Stucchi M and The SHARE Consortium (2015). "The 2013 European Seismic Hazard Model: key components and results". Bull. Earthq. Eng., 13(12): 3553-3596, doi: 10.1007/s10518-015-9795-1.

64 Standards Australia (2018). "Structural design actions, part 4: Earthquake actions in Australia". Standards Australia AS 1170.4-2007 (R2018)/Amdt 2-2018, Sydney, NSW.

65 McCue K (compiler), Gibson G, Michael-Leiba M, Love D, Cuthbertson R, Horoschun G (1993). "Earthquake Hazard Map of Australia - 1991". Australian Geological Survey Organisation, Canberra.

66 Van Houtte C and Abbott E (2019). "OpenQuake implementation of the Canterbury Seismic Hazard Model". Seism. Res. Lett., 90(6): 2227-2235, doi: 10.1785/0220190100.

67 Stirling M, McVerry G, Gerstenberger M, Litchfield N, Van Dissen R, Berryman K, Barnes P, Wallace L, Villamor P, Langridge R, Lamarche G, Nodder S, Reyners M, Bradley B, Rhoades D, Smith W, Nicol A, Pettinga J, Clark K and Jacobs K (2012). "National Seismic Hazard Model for New Zealand: 2010 update". Bull. Seism. Soc. Am., 102(4): 1514-1542, doi: 10.1785/0120110170.

68 Leyendecker EV, Hunt RJ, Frankel AD and Rukstales KS (2000). "Development of maximum considered earthquake ground motion maps". Earthq. Spectra, 16(1): 21-40, doi: 10.1193/1.1586081.

69 Standards New Zealand (2004). "Structural design actions, part 5: Earthquake actions - New Zealand". Standards New Zealand NZS 1170.5:2004, Wellington, NZ, pp. 76.

70 McVerry GH (2003). "From hazard maps to code spectra for New Zealand". 2003 Pacific Conference on Earthquake Engineering, Christchurch, Paper Number 034.

71 Burbidge DR (2012). "The 2012 Australian Earthquake Hazard Map". in, Geoscience Australia Record 2012/71, pp. 116.

72 Leonard M, Burbidge D and Edwards M (2013). "Atlas of seismic hazard maps of Australia: seismic hazard maps, hazard curves and hazard spectra". Geoscience Australia Record 2013/41, pp. 39. 
73 Nordenson GJP and Bell GR (2000). "Seismic design requirements for regions of moderate seismicity". Earthq. Spectra, 16(1): 205-225, doi: 10.1193/1.1586091.

74 Bradley BA (2015). "Benefits of site-specific hazard analyses for seismic design in New Zealand". Bull. New Zeal. Soc. Earthq. Eng., 48(2): 92-99, doi: 10.5459/bnzsee.48.2.92-99

75 Lam NTK and Wilson JL (2008). "The new response spectrum model for Australia". Electron. J. Struct. Eng., 8 Special Issue: Earthquake Engineering in the low and moderate seismic regions of Southeast Asia and Australia, 6-24.

76 Bommer JJ and Pinho R (2006). "Adapting earthquake actions in Eurocode 8 for performance-based seismic design". Earthq. Eng. Struct. D., 35: 39-55, doi: 10.1002/eqe.530.

77 Chandler AM, Lam NTK, Wilson JL and Hutchinson GL (2001). "Response spectrum modelling for regions lacking earthquake records". Electron. J. Struct. Eng., 1(1): 2-14.

78 McGuire RK (1977). "Seismic design spectra and mapping procedures using hazard analysis based directly on oscillator response". Earthq. Eng. Struct. D., 5(3): 211234, doi: 10.1002/eqe.4290050302.

79 CSA Group (2014). "Canadian Highway Bridge Design Code". Canadian Standards Association CSA S6-14, pp. 894.

80 Saroukos R (2019). "Insurance claims roll in after 7.2 magnitude earthquake as damage to Darwin homes revealed". NT News, Published 25 June 2019, Retrieved 19 August 2019, from https://www.ntnews.com.au/news/insurance-claims-rollin-after-72-magnitude-earthquake-as-damage-to-darwinhomes-revealed/newsstory/4a066632f21b0418bfada4f5789b6895.

81 Harmsen S and Frankel A (2001). "Geographic deaggregation of seismic hazard in the United States". Bull. Seism. Soc. Am., 91(1): 13-26, doi: 10.1785/0120000007.

82 Luco N, Bachman RE, Crouse CB, Harris JR, Hooper JD, Kircher CA, Caldwell PJ and Rukstales KS (2015). "Updates to building-code maps for the 2015 NEHRP Recommended Seismic Provisions". Earthq. Spectra, 31(S1): S245-S271, doi: 10.1193/042015EQS058M.

83 Kircher CA (2017). "New site-specific ground motion requirements of ASCE 7-16". 2017 SEAOC Convention, San Diego, CA.

84 Halchuk S, Adams J and Allen TI (2016). "Fifth Generation Seismic Hazard Model for Canada: crustal, inslab, and interface hazard values for southwestern Canada". Geological Survey of Canada Open File 8090, pp. 19, doi: 10.4095/299244.

85 Petersen MD, Shumway AM, Powers PM, Mueller CS, Moschetti MP, Frankel AD, Rezaeian S, McNamara DE, Luco N, Boyd OS, Rukstales KS, Jaiswal KS, Thompson EM, Hoover SM, Clayton BS, Field EH and Zeng Y (2019). "The 2018 update of the US National Seismic Hazard Model: overview of model and implications". Earthq. Spectra: doi: 10.1177/8755293019878199.

86 Building Seismic Safety Council (2004). "NEHRP Recommended Provisions for seismic regulations for new buildings and other structures, 2003 edition". Federal Emergency Management Agency 450, Washington, D.C., pp. 338.

87 Borcherdt RD (1994). "Estimates of site-dependent response spectra for design (methodology and justification)". Earthq. Spectra, 10(4): 617-653, doi: 10.1193/1.1585791.

88 Seyhan E and Stewart JP (2014). "Semi-empirical nonlinear site amplification from NGA-West 2 data and simulations". Earthq. Spectra, 30(3): 1241-1256, doi: 10.1193/063013EQS181M.

89 Dowling J, Finn WDL, Ventura CE, Bebamzadeh A and Fairhurst M (2016). "An alternative approach to site factors for NBCC 2015". Can. J. Civ. Eng., 43: 1017-1024, doi: 10.1139/cjce-2015-05.

90 Kolaj M, Allen T, Mayfield R, Adams J and Halchuk S (2019). "Ground-motion models for the $6^{\text {th }}$ Generation Seismic Hazard Model of Canada". 12th Canadian Conference on Earthquake Engineering, Québec City, Québec, Paper 192-hHtH-159.

91 Adams J, Allen T, Halchuk S and Kolaj M (2019). "Canada's $6^{\text {th }}$ Generation Seismic Hazard Model, as prepared for the 2020 National Building Code of Canada". 12th Canadian Conference on Earthquake Engineering, Québec City, Québec., Paper 192-Mkvp-139.

92 Castellaro S, Mulargia F and Rossi PL (2008). "Vs30: proxy for seismic amplification?". Seism. Res. Lett., 79(4): 540-543, doi: $10.1785 / \mathrm{gssrl} .79 .4 .540$

93 Hassani B and Atkinson GM (2016). "Applicability of the NGA-West2 site-effects model for Central and Eastern North America". Bull. Seism. Soc. Am., 106(3): 13311341, doi: 10.1785/0120150321.

94 Bradley BA (2013). "A New Zealand-specific pseudospectral acceleration ground-motion prediction equation for active shallow crustal earthquakes based on foreign models". Bull. Seism. Soc. Am., 103(3): 18011822, doi: 10.1785/0120120021.

95 Chiou BS-J and Youngs RR (2008). "An NGA model for the average horizontal component of peak ground motion and response spectra". Earthq. Spectra, 24(1): 173-215, doi: 10.1193/1.2894832

96 Algermissen ST and Perkins DM (1976). "A probabilistic estimate of maximum accelerations in rock in the contiguous United States". US Geological Survey OpenFile Report 76-416.

97 Standards Australia (1993). "Structural design actions, part 4: Earthquake actions in Australia". Standards Australia AS 1170.4-1993, Homebush, NSW.

98 Hanks TC, Beroza GC and Toda S (2012). "Have recent earthquakes exposed flaws in or misunderstandings of probabilistic seismic hazard analysis?". Seism. Res. Lett., 83(5): 759-764, doi: 10.1785/0220120043.

99 Ward SN (1995). "Area-based tests of long-term seismic hazard". Bull. Seism. Soc. Am., 85(5): 1285-1298.

100 Allen TI, Wald DJ, Earle PS, Marano KD, Hotovec AJ, Lin $K$ and Hearne M (2009). "An Atlas of ShakeMaps and population exposure catalog for earthquake loss modeling". Bull. Earthq. Eng., 7(3): 701-718, doi: 10.1007/s10518-009-9120-y.

101 Wilson JL, Lam NTK and Pham L (2008). "Development of the New Australian Earthquake Loading Standard". EJSE Special Issue, Earthquake Engineering in the low and moderate seismic regions of Southeast Asia and Australia (2008): 25-31.

102 Federal Emergency Management Agency (2004). "NEHRP Recommended Provisions for seismic regulations for new buildings and other structures, Part 2: Commentary". Federal Emergency Management Agency 450-2 / 2003 Edition, Washington, D.C., pp. 385. 
103 Heidebrecht AC (2003). "Overview of seismic provisions of the proposed 2005 edition of the National Building Code of Canada". Can. J. Civ. Eng., 30(2): 241-254, doi: 10.1139/102-068.

104 Stein S, Tomasello J and Newman A (2003). "Should Memphis build for California's earthquakes?". EOS, 84(19): 184-185, doi: 10.1029/2003EO190002.

105 Searer GR, Freeman SA and Paret TF (2007). "Does it make sense from engineering and economic perspectives to design for a 2475 -year earthquake?". in: S. Stein, S. Mazzotti (Eds.) Continental intraplate earthquakes: science, hazard, and policy issues, The Geological Society of America, Boulder, CO, 353-361.

106 Allen TI and Luco N (2018). "Opportunities to enhance seismic demand parameters for future editions of the AS1170.4". Australian Earthquake Engineering Society 2018 Conference, Perth, Western Australia.

107 Frankel A, McGarr A, Bicknell J, Mori J, Seeber L and Cranswick E (1990). "Attenuation of high-frequency shear waves in the crust: measurements from New York State, South Africa, and southern California". J. Geophys. Res., 95(B11): 17441-17457, doi: 10.1029/JB095iB11p17441.

108 Porter KA (2016). "Safe enough? A building code to protect our cities and our lives". Earthq. Spectra, 32(2): 677-695, doi: 10.1193/112213EQS286M.

109 Bairoch P and Goertz G (1986). "Factors of urbanisation in the nineteenth century developed countries: a descriptive and econometric analysis". Urban Stud., 23(4): 285-305, doi: 10.1080/00420988620080351.

110 Humar J (2015). "Background to some of the seismic design provisions of the 2015 National Building Code of Canada". Can. J. Civ. Eng., 42: 940-952, doi: 10.1139/cjce-2014-0385.

111 Douglas J, Ulrich T and Negulescu C (2013). "Risktargeted seismic design maps for mainland France". Nat.
Hazards, 65: 1999-2013, doi: 10.1007/s11069-012-04606.

112 Silva V, Crowley H and Bazzurro P (2016). "Exploring risk-targeted hazard maps for Europe". Earthq. Spectra, 32(2): 1165-1186, doi: 10.1193/112514EQS198M.

113 Malhotra PK (2005). "Return period of design ground motions". Seism. Res. Lett., 76(6): 693-699, doi: 10.1785/gssrl.76.6.693.

114 Luco N, Ellingwood BR, Hamburger RO, Hooper JD, Kimball JK and Kircher CA (2007). "Risk-targeted versus current seismic design maps for the conterminous United States". SEAOC 2007, Squaw Creek, California.

115 Frankel A (2013). "Comment on "Why earthquake hazard maps often fail and what to do about it" by S. Stein, R. Geller, and M. Liu". Tectonophys.: doi: 10.1016/j.tecto.2012.1011.1032.

116 Adams J (2019). "A 65-year history of seismic hazard estimates in Canada". 12th Canadian Conference on Earthquake Engineering, Québec City, Québec., Paper 192-cSSQ-149.

117 Tsang H-H, Daniell JE, Wenzel F and Wilson JL (2019). "A universal approach for evaluating earthquake safety level based on societal fatality risk". Bull. Earthq. Eng., doi: 10.1007/s10518-019-00727-9.

118 Kulkarni RB, Youngs RR and Coppersmith KJ (1984). "Assessment of confidence intervals for results of seismic hazard analysis". $8^{\text {th }}$ World Conference on Earthquake Engineering, San Francisco, California, 263-270.

119 Douglas J, Ulrich T, Bertil D and Rey J (2014). "Comparison of the ranges of uncertainty captured in different seismic-hazard studies". Seism. Res. Lett., 85(5): 977-985, doi: 10.1785/0220140084.

120 Stein S, Geller RJ and Liu M (2012). "Why earthquake hazard maps often fail and what to do about it". Tectonophys., $\quad \mathbf{5 6 2 - 5 6 3}$ : $1-25, \quad$ doi: 10.1016/j.tecto.2012.06.047. 